\title{
Caregiving process and caregiver burden: Conceptual models to guide research and practice
} Parminder Raina*1,4,9, Maureen O'Donnell ${ }^{5}$, Heidi Schwellnus ${ }^{3}$, Peter Rosenbaum 1,2,3,4, Gillian King 3,7, Jamie Brehaut ${ }^{6}$, Dianne Russell1,3,4, Marilyn Swinton ${ }^{4}$, Susanne King ${ }^{3,4}$, Micheline Wong 5 , Stephen D Walter ${ }^{1,4}$ and Ellen Wood ${ }^{8}$

\author{
Address: ${ }^{1}$ McMaster University, Department of Clinical Epidemiology and Biostatistics, Hamilton, Ontario, Canada, ${ }^{2} \mathrm{McMaster}$ University, \\ Department of Pediatrics, Hamilton, Ontario, Canada, ${ }^{3}$ School of Rehabilitation Science, McMaster University, Hamilton Ontario, Canada, \\ ${ }^{4}$ CanChild Centre for Childhood Disability Research, McMaster University, Hamilton, Ontario, Canada, ${ }^{5}$ Centre for Community Child Health \\ Research, BC Research Institute for Children's and Women's Health, University of British Columbia, Vancouver, British Columbia, Canada, \\ ${ }^{6}$ Ottawa Health Research Institute, Clinical Epidemiology Unit, Ottawa, Ontario, Canada, ${ }^{7}$ Thames Valley Children's Centre, London, Ontario, \\ Canada, ${ }^{8}$ Department of Pediatrics, Dalhousie University, Halifax, Nova Scotia, Canada and ${ }^{9}$ McMaster University Evidence-based Practice Centre, \\ McMaster University, Hamilton, Ontario, Canada \\ Email: Parminder Raina* - praina@mcmaster.ca; Maureen O'Donnell - modonnell@cw.bc.ca; \\ Heidi Schwellnus - heidi.schwellnus@utoronto.ca; Peter Rosenbaum - rosenbau@mcmaster.ca; Gillian King - gilliank@tvcc.on.ca; \\ Jamie Brehaut - jbrehaut@ohri.ca; Dianne Russell - russelld@mcmaster.ca; Marilyn Swinton - swinton@mcmaster.ca; \\ Susanne King - kings@mcmaster.ca; Micheline Wong - mmwong15@hotmail.com; Stephen D Walter - walter@mcmaster.ca; \\ Ellen Wood - ewood@is.dal.ca \\ * Corresponding author
}

Published: 14 January 2004

BMC Pediatrics 2004, 4:I
Received: 05 May 2003

Accepted: 14 January 2004

This article is available from: http://www.biomedcentral.com/|47|-243|/4/I

(C) 2004 Raina et al; licensee BioMed Central Ltd. This is an Open Access article: verbatim copying and redistribution of this article are permitted in all media for any purpose, provided this notice is preserved along with the article's original URL.

\begin{abstract}
Background: Parental care for a child with a developmental disability is an enormous responsibility, one that can far exceed that of typical parental care. While most parents adapt well to the situation of caring for a child with a disability, some do not. To understand parents' adaptations to their children's disabilities, the complex nature of stress processes must be accounted for and the constructs and factors that play a role in the caregiving must be considered.

Discussion: Evidence suggests that there is considerable variation in how caregivers adapt to their caregiving demands. Many studies have sought to qualify the association between caregiving and health outcomes of the caregivers. Contextual factors such as SES, child factors such as child behaviour problems and severity of disability, intra-psychic factors such as mastery and self-esteem, coping strategies and social supports have all been associated with psychological and/or physical outcome or parents or primary caregivers. In reviewing these issues, the literature appears to be limited by the use of traditional analytic approaches which examine the relationship between a factor and an outcome. It is clear, however, that changes to single factors, as represented in these studies, occur very rarely even in the experimental context. The literature has also been limited by lack of reliance on specific theoretical frameworks.

Summary: This conceptual paper documents the state of current knowledge and explores the current theoretical frameworks that have been used to describe the caregiving process from two diverse fields, pediatrics and geriatrics. Integration of these models into one comprehensive model suitable for this population of children with disabilities and their caregivers is proposed. This model may guide future research in this area.
\end{abstract}




\section{Background}

It has been estimated that about $10 \%$ of children experience developmental disorders requiring access to the health care system and extensive caregiving, often throughout childhood and into the adult years. The cerebral palsies (CP) are one such chronic condition, and can serve as a prototype of childhood disability. CP presents in early childhood as a set of functional limitations that stem from disorders of the developing central nervous system [1]. The current estimated incidence of CP is 2.0-2.5 per 1000 live births[2,3]. Although impaired motor function is the hallmark of the cerebral palsies, many children also experience sensory and intellectual impairments, and may have complex limitations in self-care functions such as feeding, dressing, bathing, and mobility. These limitations can result in requirements for long-term care far exceeding the usual needs of children as they develop, or the expectations of their families as they parent $[4,5]$. Thus while caregiving is a normal part of being the parent of any young child, providing the high level of care required by a child with long-term functional limitations can become burdensome and may impact upon both the physical and psychological health of the caregiver.

For each individual there may exist a number of psychosocial mechanisms that regulate the impact of stress on health and well-being. The characteristics of the caregiver, the recipient of care, their shared history, and the social, economic and cultural contexts within which they find themselves combine to create an infinite variety of circumstances from which stress may both originate and be managed. Nonetheless, there are implications arising from the role itself that help to explain some of the common patterns of stress and stress outcomes (e.g., deteriorating self concept, decline in emotional well being) in caregivers. Individuals typically occupy multiple roles in life, such as family roles and occupational roles. Becoming a caregiver of a child with long-term disability introduces an additional role, and therefore will require some rearrangement of priorities, and redirection of energy[8]. Not only is this likely to produce strain at a personal level, but it is also likely to spur reactions (potentially negative) from various people who are interconnected to a person through his or her roles outside the realm of caregiving. Thus stress can be understood to arise at the level of provision of care, as well as in other areas of life. Much of the literature tends to focus on stress related to direct provision of care, however, as Aneshensel et al. (1995) suggest, it is important to recognize stress occurring in the broader social context in order to gain a complete understanding of its scope and effects[8].

Over the past two decades, family units have become smaller and the rate of marriage breakdown has increased[6]. In the same period, with the technological advance in medicine, the survival of children with disabilities has risen[7]. The shift of healthcare to ambulatory and community-based care settings may serve to increase demands on family members, necessitating that they be more active participants in the care of their child. This combination of factors leaves smaller family units shouldering the responsibility for increased caregiving demands, making the task of understanding and providing for the needs of the caregiver more important.

As reported in both the scientific and lay press, those experiencing what has been called the unexpected 'career' of 'caregiver for a child with a disability' may experience a multifaceted, complex and stressful life situation that can have important consequences if the health care and social service systems cannot recognize these issues and assist such families. Like an occupational career, the notion of a 'caregiver career' connotes a dynamic process, where an individual proceeds through a sequence of stages, necessitating considerable transitions and restructuring of responsibility over time[8]. For a caregiver, these stages include preparation for and acquisition of the caregiver role, enactment of the associated tasks and responsibilities, and eventual disengagement from the role[8]. Many patterns of change also exist within these stages, such as the need for increased assistance with activities of daily living (ADLs).

This metaphorical description of the caregiving experience provides a useful way to consider the predicaments that many families may experience as they raise a child with chronic problems of health or development. Note, however, that the 'caregiver career' differs from an occupational career in several important respects. Becoming an informal caregiver is not typically chosen or planned; people do not often envision being in a caregiver role when they project themselves into the future[8]. Thus, preparation for this role will most often occur once it has already been acquired[8]. In addition, an informal caregiver lacks the rights, privileges, and prerogatives that come along with a formal career status. This is not usually a career recognized by society as a worthwhile pursuit. The role also differs from occupational careers in that progression along its pathway is driven not by ambition, but rather by the progression of the disorder and the functional dependencies it creates. Finally, unlike an occupational career choice, the caregiving career cannot be entered into and left at one's own will.

The relationship between caregiving and health is described generally in terms of stress. Aneshensel et al. defined stressors in the context of caregiving as "the problematic conditions and difficult circumstances experienced by caregivers (i.e. the demands and obstacles that exceed or push to the limit one's capacity to adapt)". 
Emphasized in this conceptualization is that stress originates at an intersection between one's external environment and internal state; it arises "when the demands imposed by a patient's condition collide with a caregiver's subjective ability to respond, or when these demands obstruct the pursuit of other objectives"[8]. This intersection between the individual and his or her environment serves to explain why some caregivers seem less affected by caregiving stress, while others experience more deleterious health outcomes.

The potential compromise of caregiver health brought on by the demands of the role is poignantly exemplified in a well-publicized Canadian story (known as the Latimer case) where a father had taken the extreme action of killing his child with a disability. The father's explanation for committing this act emphasized the feelings of stress he experienced related to taking care of his child, the child's degree of pain, and his sense of helplessness regarding the future life his child would have. This case caused a considerable amount of controversy between two coalitions: those representing the rights of people with disabilities and those who believe that "mercy killing or assisted suicide" is sometimes justified. The case was finally resolved through the Supreme Court of Canada and resulted in a charge against the father of second degree murder with a 10 year sentence. The court upheld the principle that every individual's life, with or without a disability, is to be treated equally in society and receive the full protection of the law. It is interesting to note that this decision did not receive popular support as the majority of people polled felt the decision was wrong, that killing his daughter was excusable based on the consequences of her disability. This is a strong reflection of the public's perception that caring for an individual with a disability must be extremely stressful and not necessarily worth the effort.

What are the mediating factors in the stress and time demands of caring for a child with a disability? Why do some families cope very well and others less well? To understand parents' adaptations to their children's disabilities, it is necessary to take into account the complex nature of the stress process and attempt to describe the constructs and factors that play a role in the caregiving experience.

Theories guide research and in turn, research results modify theories. To begin the task of understanding the complex processes of caregiving, current research evidence must first be considered critically and objectively, to provide an up-to-date foundation of knowledge and to identify limitations. This includes identifying and addressing areas of research beyond childhood developmental disorders, in particular the literature on the challenges faced by adults caring for a functionally dependent spouse or par- ent, in which a substantial branch of research is focused on the needs and health of caregivers. Existing theoretical models describing caregiver health must be examined, and then critically considered with respect to the current state of evidence. Development of a conceptual model attempting to explain health of caregivers of children with disabilities can then be accomplished through synthesizing and building upon these current frameworks to provide a more comprehensive picture of the multi-factorial nature of caregiver health.

The objective of this paper is to document this process of evidence review and model creation. Relevant research will be reported and current conceptual models discussed. Based on this literature, a new conceptual model will then be proposed which is amenable to testing through empirical research. With this new model we hope to predict profiles of stress situations and thus identify vulnerable families, as well as factors that mediate the experience of stress and moderate the impact of childhood disability on parental well-being. This should make it possible for services to be targeted to help ameliorate these situations before the health of those providing care becomes seriously compromised.

\section{Discussion \\ What has been done}

Most of the studies conducted in this field of parent wellbeing in the context of chronic childhood impairments involve a survey with a variety of questionnaires, or either structured or unstructured interviews conducted with caregivers. The present review was not intended to be comprehensive. The review only included studies that were published in English in peer-review journals. The search was performed on following four databases: (1) MEDLINE, (2) CINAHL, (3) PsychINFO, and (4) Sociological Abstracts. These databases were searched from their date of release to the end of 2002. The search was conducted using combinations of the search terms and included terms such as "caregiv*" or "care giv*" or "parent" or "mother" or "father" or "informal care", "child health", "child disability" and "pediatrics". In addition, we also examined the reference lists of all included papers to identify any additional articles that might have been missed by our search strategy. Table 1 summarizes studies examining the factors involved in caregiver stress. However, we have also explored the key studies from the geriatric literature to identify factors that might be relevant to the caregiving process in a pediatric population (Table 2). Evidence suggests that there is considerable variation in how parents adapt to this caregiving demand $[9,10]$. Some adapt well to the challenges of caring for a child with a disability, while others do not. The typical outcomes studied relate to caregiver physical and mental health, their wellbeing, as well as their ability to maintain their social roles. 
Table I: Studies Investigating Health and Well-being of Caregivers of Children with Disabilities

\begin{tabular}{|c|c|c|}
\hline Author \& Year & Sample & Factors Investigated \\
\hline $\begin{array}{l}\text { Barakat \& Linney[46] } \\
\text { I992 }\end{array}$ & $\begin{array}{l}29 \text { families of children with spina } \\
\text { bifida and without mental } \\
\text { retardation and } 28 \text { families of } \\
\text { children without handicaps }\end{array}$ & $\begin{array}{l}\text { Interrelation of maternal } \\
\text { adjustment, mother-child } \\
\text { interaction, and child } \\
\text { adjustment }\end{array}$ \\
\hline Beckman[25] 1983 & $\begin{array}{l}\text { 3I parents of infants with } \\
\text { disabilities }\end{array}$ & $\begin{array}{l}\text { Determine the extent to } \\
\text { which specific kinds of } \\
\text { behavior and } \\
\text { characteristics of the } \\
\text { child were related to } \\
\text { stress reported by } \\
\text { mothers }\end{array}$ \\
\hline $\begin{array}{l}\text { Breslau, Staruch \& } \\
\text { Mortimer[5] } 1982\end{array}$ & $\begin{array}{l}369 \text { mothers of children with a } \\
\text { disability and } 456 \text { mothers of } \\
\text { children without }\end{array}$ & $\begin{array}{l}\text { Psychological distress of } \\
\text { mothers Child's } \\
\text { dependence in ADL }\end{array}$ \\
\hline
\end{tabular}

Cadman, Rosenbaum, Epidemiological study Data from Boyle \& Offord[II] |99|
I37 parents, 96 mothers, 4 | fathers, of children in pre-school children in early intervention services

\section{Dyson[13] $1993 \quad 38$ parents of children with disabilities and 34 parents of children without disabilities}

Erikson \& Upshur[45] 1989

Freidrich, Wilturner \& Cohen[26] 1985

Frey, Greenberg, \& Fewell[27] 1989

Friedrich[44] 1979

Friedrich \&

Friedrich[17] 1981
202 mothers of children with and without disabilities

I 12 of mothers with children with developmental delay

48 mothers and 48 fathers of children with handicaps
98 mothers of children with a variety of disabilities

34 parents of disabled children compared to a control group of parents of children without disabilities
Individual parent mental health, family functioning in families of children with and without disabilities Physical health Family functioning

Personal well-being, attitudes towards the child, family integrity, child functioning, parentchild play ops, and child behavior and development

Parental stress and family functioning over two time periods

Caretaking burden and social support

Buffers of stress Utilitarian resources Energy/morale General and specific beliefs Social support

Relations of child characteristics, family social network, parent belief systems and coping styles to parent outcomes

Predictors of coping behavior

Marital satisfaction, social support, religiosity, psychological well-being, resources and stress

\section{Associations}

Social support was related to higher maternal psychological adjustment and higher child adjustment Maternal psychological adjustment related positively to child adjustment in both groups

All but progress were significantly related to amount of stress reported Number of parents in the home was related to amount of stress reported Temperament and social responsiveness, temperament and caregiving demands and caregiving demands and social responsiveness were strong associations Number of caregiving demands was most highly related to stress Mothers of children with disabilities had a significantly higher mean score on the depression-anxiety scale Condition type did not have a statistically significant effect on either maternal distress or depression-anxiety scales Dependence in ADL did have a statistically significant difference on depression-anxiety scale and on maternal distress, the more dependent the child the greater the mother's psychological distress The critical factor affecting maternal responses was the impact of the condition on the child's level of functioning

Demographic and psychosocial variables were similar between the two groups, except for low income which was more common in the families with children with disabilities Parents of individuals with disabilities suffer an increased burden of mental health and adjustment problems, or may be more apt to seek assistance Overall the families were similar, contrasting to clinic based studies where the sample bias may skew the results Single mothers have more financial problems Mothers reported poorer emotional and physical health and more time demands from child Those with more satisfaction with social supports reported fewer emotional and physical problems More pessimistic about older children's future Social support mediates well-being even with a child with a disability

High level of stability in parental stress and modest degree of consistency in family functioning in families with children with disabilities Families of children with disabilities had a higher level of stress at both time periods

Significant associations were found on difficulty of and time devoted to caretaking, number of tasks with which fathers helped, and satisfaction with support from family, friends, and community groups.

Depression increased in mothers from time 1 to 2

Child characteristics predicted parenting stress Parental belief systems predicted all 3 parental outcomes Social network predicted family adjustment Psychological distress was low in mothers with "positive belief system, or non-critical family network" Support multidimensional evaluation of family characteristics that mediate the impact of a child with a disability

Marital satisfaction was best predictor of mothers coping, Residence of the child was also a factor, those with children in institutions were more stressed and mothers of female children reported more stress

Families of children with disabilities experience more stress and less marital satisfaction, psychological wellbeing, social support and religiosity 
Table I: Studies Investigating Health and Well-being of Caregivers of Children with Disabilities (Continued)

\begin{tabular}{|c|c|c|}
\hline $\begin{array}{l}\text { Gowen, Johnson- } \\
\text { Martin, Davis } \\
\text { Goldman, \& } \\
\text { Applebaum[14] } 1989\end{array}$ & $\begin{array}{l}41 \text { infants, } 21 \text { with a disability, } 20 \\
\text { without and their mothers (varying } \\
\text { diagnoses) Multiple time survey. } \\
\text { II. } 15,19 \text { and } 29 \text { mos. }\end{array}$ & $\begin{array}{l}\text { Depression in mothers } \\
\text { related to child } \\
\text { characteristics or social } \\
\text { support. }\end{array}$ \\
\hline $\begin{array}{l}\text { Silver, Westbrook, \& } \\
\text { Stein[55] } 1998\end{array}$ & $\begin{array}{l}770 \text { randomly selected in } 1991 \text { and } \\
1992 \text { from two samples with } \\
\text { children under } 18 \text { year of age }\end{array}$ & $\begin{array}{l}\text { Health status inventory } \\
\text { Parents psychological } \\
\text { distress }\end{array}$ \\
\hline
\end{tabular}

Kazak \& Marvin[15] 1984

Leonard, Johnson, \& Brust[30] 1993

McKinney \&

Peterson[12] 1985

Quittner, Glueckauf, 96 mothers of deaf children, and

\& Jackson[58] $1990 \quad$ I 18 matched controls

Saddler, Hillman, \& Benjamins[29] 1993

Sloper \& Turner[9] 1993

Trute \& HiebertMurphy[32] 2002

Wallander, Varni, Babani DeHaan, Thompson Wilcox, \& Palsy (CP), Banis[10] 1989
56 families with a child with SB and a group of 53 families without a handicapped child, matched for child's

Two groups, those "OK" and "NOT OK" (more severely impaired) 132 of 220 selected families, only women's responses were used

67 mothers, convenience sample, Children with Developmental Disabilities (DD)

I 39 two-parent families of children with cerebral palsy $(n=48)$, diabetes $(n=46)$ and able bodied children $(n=45)$

107 families, mothers and fathers completed questionnaires separately

Random sample of 87 families of children with developmental disabilities, final $n=64$

50 mothers of children with either Social Behaviour (SB) or Cerebral
Roles played and social network

How the caregivers were managing giving care to children with disabilities

Predictors of stress, perceived control, social support, unusual caregiving demands, programs

Contrasted the "buffer" model of social support with an alternative mediator model for ongoing parenting stress vs. life event stress

Effect of visibility or severity of disability on family functioning

Descriptor variables of child characteristics, life events, satisfaction with life and adaptation to the child

Interviewed twice, initially while children with developmental disabilities were in the preschool years, and again 7 years later

Utilitarian resources, Child adjustment Psychosocial family resources Service utilization
Perception of how difficult the child was to care for was positively related to maternal depression at 17 and 29 mos. No significant difference in mothers in relation to parenting competence

Grouped parents by 3 domains, functional limitations, reliance on compensatory mechanisms, and service use Chronic health condition was a key factor Risk of psychological distress may depend upon the types of consequences experienced by the children, functional impairment of children related to poorer parental adjustment Parents with children with functional limitations may be at high risk

Mothers experienced more stress, fathers were similar to control. Generally, higher levels of stress and distinct network structures were found for the families with handicapped children. Number in network doesn't relate to effectiveness of group

Mothers of those "NOT OK" were in poorer physical and mental health, had greater demands placed on their time and finances, and received less emotional support from family and friends. Special programs provided some assistance but not enough to meet their needs

Peer support one of the most important factors Sense of competence was only predictor of perceived locus of control Children with DD are a source of stress, place > demands on parents

Path analyses suggested social support mediated the relationship between stressors and outcomes Chronic parenting stress associated with lowered perceptions of emotional support, and greater depression and anxiety

Parenting stress accounted for substantial variance in psychological distress scores in contrast to life events stress

Neither visibility nor severity of disability impacted family functioning, families with children with disabilities exhibited high levels of family functioning similar to control group

High levels of psychological distress, especially for mothers, greater disability and communication problems in child were risk factors, for fathers, child gender and feeding problems showed significant associations with outcomes

Interview tool found to predict parental stress

Social environment associated with mental health, social functioning but not physical health, Child's disability status not significant assoc with maternal adaptation, Longer marriage and larger family were predictive of poorer social functioning Behavioral problems were associated with poorer physical health not strongly, Better marital satisfaction and a larger support group but less family support were predictors of better social effects
Many studies have sought primarily to qualify the association between caregiving and negative health outcomes. Cadman, Rosenbaum, Boyle and Offord (1991) found parents of children with disabilities were more likely to experience depression and distress than parents of children without disabilities[11]. Another study found that caregiving for a child with a developmental disability places increased demands on the caregivers[12]. Dyson 
Table 2: Key Studies Investigating Health and Well-being of Caregivers of the Elderly

\begin{tabular}{|c|c|c|c|}
\hline Author \& Year & Sample & Factors investigated & Associations \\
\hline $\begin{array}{l}\text { Caserta, Lund \& } \\
\text { Wright[50] } 1996\end{array}$ & 160 caregivers & $\begin{array}{l}\text { Examine the multidimensional nature } \\
\text { of caregiver burden by analyzing the } \\
\text { patterns of association between } 5 \\
\text { dimensions of burden }\end{array}$ & $\begin{array}{l}\text { Time dependence was the most influenced by patient } \\
\text { impairment and caregiving involvement Emotional burden } \\
\text { was largely a function of caregiving satisfaction Physical } \\
\text { health measures explained little variance in physical } \\
\text { burden, which was mostly explained by depression } \\
\text { Findings lend support to a multidimensional view of } \\
\text { burden }\end{array}$ \\
\hline $\begin{array}{l}\text { Evans, Bishop \& } \\
\text { Ousley[42] } 1992\end{array}$ & $\begin{array}{l}\text { I8I caregivers in final } \\
\text { sample }\end{array}$ & $\begin{array}{l}\text { Assessed positive, neutral and } \\
\text { negative aspects of caregiving And } \\
\text { impact of caregiving on family } \\
\text { functioning }\end{array}$ & $\begin{array}{l}\text { No clinical or statistical difference, although moderately } \\
\text { more anxiousness, depressive and somatic symptoms } \\
\text { were reported during the duration of the caregiving } \\
\text { experience Family relation s seemed to be a source of } \\
\text { strength }\end{array}$ \\
\hline $\begin{array}{l}\text { Kiecolt-Glaser, } \\
\text { Dura, Speicher, } \\
\text { Trask, Glaser[39] } \\
\text { I99I }\end{array}$ & $\begin{array}{l}69 \text { spousal caregivers } \\
\text { with > } 5 \text { years in role } \\
\text { compared to matched } \\
\text { controls } 13 \text { month time } \\
\text { frame }\end{array}$ & $\begin{array}{l}\text { Depression, immune function and } \\
\text { health }\end{array}$ & $\begin{array}{l}\text { Caregivers show decreases in cellular immunity, more } \\
\text { days of infectious illness, greater incidence of depressive } \\
\text { disorders, those who had less social support, and were } \\
\text { most distressed by their role showed the greatest } \\
\text { negative changes in immune function }\end{array}$ \\
\hline $\begin{array}{l}\text { Mittleman, Ferris, } \\
\text { Shulman, Steinberg, } \\
\text { Ambinder, Mackell } \\
\text { \& Cohen[23] } 1995\end{array}$ & $\begin{array}{l}206 \text { spouse-caregivers } \\
\text { randomly assigned to } \\
\text { either treatment or } \\
\text { control group, } 173 \\
\text { completed the study }\end{array}$ & $\begin{array}{l}\text { Psychosocial intervention program } \\
\text { (individual family counseling, } \\
\text { continuous ad-hoc counseling } \\
\text { availability, and support groups) and } \\
\text { depression in caregivers of } \\
\text { Alzheimer's patients }\end{array}$ & $\begin{array}{l}\text { After I year, control group became increasingly } \\
\text { depressed while intervention group remained stable; by } \\
\text { the } 8^{\text {th }} \text { month, treated caregivers were significantly less } \\
\text { depressed than control group Suggests enhancing long- } \\
\text { term social support can have a significant impact on } \\
\text { depression in caregivers }\end{array}$ \\
\hline $\begin{array}{l}\text { MaloneBeach E, } \\
\text { Zarit S \& Farbman } \\
D[60] 1995\end{array}$ & $\begin{array}{l}43 \text { family caregivers to } \\
\text { demented elders }\end{array}$ & $\begin{array}{l}\text { Relationship of daily mood and daily } \\
\text { events in a caregiving context }\end{array}$ & $\begin{array}{l}\text { Some caregivers are highly distressed by caregiving } \\
\text { demands, some report moderate levels of distress, and } \\
\text { others show no relationship between mood and daily } \\
\text { events }\end{array}$ \\
\hline $\begin{array}{l}\text { Morrissey, Becker } \\
\text { \& Rupert[5I] } 1990\end{array}$ & $\begin{array}{l}47 \text { spouses of patients } \\
\text { with } A D \text { caring form } \\
\text { them in the home }\end{array}$ & $\begin{array}{l}\text { Marriage, work, recreation and mood } \\
\text { were investigated as a function of } \\
\text { patient's disability level and coping } \\
\text { resources which were available or } \\
\text { used }\end{array}$ & $\begin{array}{l}\text { Patient's disability level has more negative impact on the } \\
\text { caregiver's marriage and recreation, work had a reverse } \\
\text { relationship }\end{array}$ \\
\hline $\begin{array}{l}\text { Schulz, O'Brien, } \\
\text { Bookwala, } \\
\text { Fleissner[22] } 1995\end{array}$ & $\begin{array}{l}\text { Review of the literature } \\
\text { of caregiving for adults } \\
\text { with AD }\end{array}$ & Depressive symptoms & $\begin{array}{l}\text { Virtually all studies report elevated levels of depressive } \\
\text { symptoms among caregivers. }\end{array}$ \\
\hline Sisk, R[52] 2000 & $\begin{array}{l}\text { I2I predominantly } \\
\text { female caregivers, mean } \\
\text { age } 61.1 \text { years }\end{array}$ & $\begin{array}{l}\text { Perception of burden and health- } \\
\text { promoting behaviors of caregivers }\end{array}$ & $\begin{array}{l}\text { Those perceiving lower subjective burden practice more } \\
\text { health-promoting behaviors than those with higher } \\
\text { subjective burden scores }\end{array}$ \\
\hline $\begin{array}{l}\text { Skaff M, Pearlin L, } \\
\text { Mullen J[33] } 1996\end{array}$ & $\begin{array}{l}456 \text { spouses and adult } \\
\text { children caring for a } \\
\text { family member with } \\
\text { Alzheimer's disease }\end{array}$ & $\begin{array}{l}\text { The impact of transitions in careers of } \\
\text { Alzheimer's caregivers on their sense } \\
\text { of mastery }\end{array}$ & $\begin{array}{l}\text { For those who continue to care for their relative, mastery } \\
\text { declines; for those who place their relative in a care } \\
\text { facility, mastery remains unchanged; for those who } \\
\text { experience death of their relative, mastery increases }\end{array}$ \\
\hline
\end{tabular}

(1993) confirmed significantly higher parental stress in parents of children with disabilities, who were also found to have pessimism regarding the future[13]. In addition, the parents' perception of how difficult it was to care for the child was related to feelings of depression[14]. Much of the research has focused primarily on mothers of children with a disability. It has been shown that these mothers are more stressed than mothers of children without disabilities due to the extra daily tasks which take away time from the mothers to take care of themselves[15]. Dunst, Trivette and Cross (1986) also found that mothers of children with disabilities reported poorer emotional and physical health and that they felt that there were greater demands on their time from the child[16]. Gowen,
Johnson-Martin, Goldman and Applebaum (1989) similarly reported that mothers of children with disabilities had more difficulty caring for their children and that they felt that they could not find enough time for themselves due to the increased daily demands associated with caring for a child with a disability[14,17].

The literature supports a link between context, especially socioeconomic status (SES), and health [18-21] but results have been mixed concerning the physical and psychological health of the caregivers. In the literature concerning caregivers of the elderly, lower SES, age, and marital status of the caregiver have been shown to be linked to psychological health of the caregiver[22,23]. 
Higher SES has been associated with fewer psychological life stressors[10]and better emotional well-being[9]in caregivers of children. It is of course recognized that the SES is but one of several important indicators of the context.

In terms of how child characteristics have been shown to modify the health outcomes of caregivers, most findings concern psychological health of the caregiver. King et al. (1999) found child behavior problems to be the single most important predictor of caregiver psychological wellbeing[24]. Children's temperament has been related to feelings of depression in the caregiver and to self-rated scores of well-being and competence in mothers of children with disabilities[25]. Furthermore, severity of the disability has been repeatedly shown to be related to parental stress [26-30]. Other variables relevant to caregiver psychological health may include age and gender of the child, level of the child's communication ability, and the presence of specific cognitive or sensory impairments $[11,13,27,31,32]$. Literature examining intrapsychic factors has shown that caregivers' self-perception is related to overall caregiver health. Mastery is a concept addressing 'the general degree to which one experiences control over what goes on in his or her life' [33]. This sense of mastery has been repeatedly shown to be associated with both physical and psychological health in a variety of populations [34-36]. Similarly, low self-esteem and 'loss of self have been shown to be associated with maternal depression[35,37].

A portion of the literature has investigated various aspects of coping. Friedrich et al. (1985) showed that caregivers in difficult circumstances but with relatively high social support managed better than those with less social support[26]. The level of available informal social support has consistently been shown to be associated with both fewer reports of depression and better physical health in caregivers of the elderly[22,23,38,39]. Satisfaction with social support networks has been associated with more positive caregiver attitudes and personal wellbeing[16,24,40]. In a study of 48 mothers and 48 fathers of children with disabilities, Frey, Greenberg, and Fewell (1989) determined that "positive belief systems, or a noncritical family network" were associated with low psychological distress in mothers, and that social network predicted family adjustment[27]. Social support was investigated by McKinney and Peterson (1985), who identified peer support as one of the most important predictors of stress[12], while Dunst, Trivette and Cross (1986) demonstrated that parents who had more satisfaction with social supports reported fewer emotional and physical problems[16]. Family functioning and stress management have also been shown to serve as coping factors[9,41-43]. Freidrich (1979) showed that marital status was the best predictor of coping for mothers of chil- dren with disabilities, indicating spousal support as a coping factor[44]. This was supported by Erikson and Upsur, (1989) and Lambrenos et al. (1996)[31,45]. Specific stress management strategies can be associated with better caregiver health $[27,46]$.

\section{Limitations of the current literature}

Most of the current broadly-based studies investigating caregiver health in the child health literature do not rely on any specific theoretical frameworks that guide research into an understanding of the mechanisms by which some caregivers experience negative consequences and other do not. The majority of the published research has focused on understanding hypotheses using traditional analytical approaches that examine the relationship of a factor to the outcome after adjusting for other variables. However this method has many shortcomings. This type of study is used primarily to estimate the "independent" or direct effects of childhood disability on the "dependent" variable, in this case caregiver health. However, single factor changes are relatively rare outside of the context of a natural or laboratory experiment, as are the assumptions of linear, additive relationships and perfect measurement which are inherent to regression analysis. Moreover, few regressionbased studies look specifically for possible contingent relationships among explanatory mechanisms; regression analyses will typically assume that such interactions do not exist[47]. Although these studies have been beneficial in pointing to a wide range of possible mechanisms mediating caregiver health, they fall short of providing an integrated picture by failing to examine comprehensively the direct and indirect pathways occurring within this array of factors that may influence health outcomes. To understand the complex web of direct and indirect relationships that impact the health and well being of family caregivers, research needs to test hypotheses that are guided by theoretical frameworks, whereby these hypotheses can be tested using advanced statistical techniques such as structural equation modeling.

\section{Review of theoretical frameworks}

\section{The risk-resilience model}

The first model relating chronic illness and stress outcomes was proposed by Wallander et al[48]. Wallander and colleagues were interested in explaining why there was a wide variation in the psychological adjustment of children with chronic physical illness. Specifically, they wanted to identify what was different about children with chronic illness in terms of risk and resistance factors (coping resources). The resistance factors are separated into three categories: stable person factors, stress processing factors and social-ecological factors[48]. Wallander et al. suggest a process with changing relationships between the risk and resistance factors over time. Additional aspects within the risk factors category that may precipitate stress 
are identified, including those factors within the individual and the disability, the functional independence level of the individual and the factors related to living with a disability[48].

Building upon the risk-resilience conceptual framework, King et al. proposed a model of factors affecting the health of caregivers of children with disabilities[24]. This model adds to Wallander et al. by including a process-outcome framework. The variable of parent perception of the quality of outside care is added to the framework in relation to the prediction of parent well-being. There are four groups of terms, including prognostic indicators, professional caregiving, mediating variables and parental outcomes[24]. The constructs within the terms are demographic factors, disability parameters, caregiving process, social-ecological factors, psychosocial life stressors, coping strategies, and the two outcomes, satisfaction with care and parent emotional well-being[24]. The outcome of better parent well-being was associated with the perception of having received family-centered care, the presence of protective socio-ecological factors, fewer child behavior problems and increased satisfaction with care[24]. Their results highlight the necessity of providing services in a family-centered framework that meets the parents' needs, and support the notion that socio-ecological factors directly impact parent well-being.

\section{The caregiving stress process model}

This model was designed to assess the informal caregiving processes affecting caregiver health[35,49]. Similar to other models described above, Aneshensel et al. and Pearlin et al. applied the stress process model to the caregiving of older adults with dementia who at one point were independent but where the relationship had now changed to one where the caregiver was responsible for meeting all the needs of the older adult with dementia.

As mentioned earlier, the caregiving experience and associated stress process reflects a process that changes over time. Pearlin and colleagues define stressors as the "problematic conditions and difficult circumstances experienced by caregivers" that strain or supersede the individual's capacity to adapt[8]. These are conceptualized as primary and secondary in nature. The primary stressors are linked directly to the individual and the disability, while the secondary stressors arise from the demands of the caregiving role itself. The potential proliferation effects of the stress involved in the caregiving role highlight the existence of a complex stress process[8]. This conceptualization allows for numerous instances for the moderators to impact the situation. The moderators include social supports and concepts of mastery or selfefficacy, which determine how people are impacted differ- ently by the same stressors, and may help to sustain the caregiver and lessen the effect of the stressors[8].

The manifestations of stress (outcomes) are well-being, physical and mental health and the caregivers' ability to sustain their own social roles[8,50]. A considerable base of independent research literature supports each of these elements. Pearlin and colleagues recognize that the interrelationships among these variables change and develop over time, however what has not been researched are the processes or linkages that join these components. The Caregiving Career/Stress Process model suggests that "life events can lead to negative changes in people's roles, changes whose persistence wears away desired elements of self-concept, and that through this set of linkages stress is aroused[51,52]. Coping and social supports, for their part, can intervene at different points along this process, thereby mediating the outcomes."[35].

\section{Proposal: a multidimensional model}

Why a multidimensional model is needed

A comprehensive multidimensional model based on previous research and theory is needed to guide future research in the area of caregiver health. It will allow the researcher to model not only the direct relationships between constructs of interest and the outcomes, but also the indirect effects through intervening constructs.

The models of Pearlin et al., Wallander et. al and King et al. agree on many factors, including the importance of background variables, characteristics of the caregiving situation, characteristics of the caregiver, and social factors $[24,48,49]$. They also agree that coping factors play important roles in the caregiving process. The primary difference between these frameworks is the relative focus on informal or formal care. There are also important differences between the older adult population and that of children. The proposed model builds upon the work of these three groups by developing a hybrid model that incorporates the advantages of existing frameworks from the geriatric as well as pediatric literature, in order to gain a more complete picture of caregiving than any original model might have provided separately[35,48]. Specifically, this means:

a) Focusing on both formal and informal caregiving processes within a single comprehensive model

b) Incorporating new specific findings from King et al[24], such as the role of the formal caregiving process in the health of the caregiver

c) Separation of child disability and child behavior problems into discrete constructs 
d) Extending the King et al[24]work by examining their concept of socio-ecological factors in more detail through the constructs of family function and social support

e) Examining both physical and psychological health as outcomes in the model.

The health of caregivers of children with CP will be used as a prototype, to demonstrate the application of the proposed theoretical framework within the broader category of 'developmental disabilities'. CP comprises a heterogeneous group of neurodevelopment disorders, ranging from 'mild' motor difficulties to an array of complex developmental and functional disabilities in children with more 'severe' CP. As a group caregivers of children with $\mathrm{CP}$ will likely experience a wide range of demands, thus allowing the theoretical constructs to be broadly applicable to families of children with many different developmental disabilities.

The reason for focusing on caregiver health and wellbeing as an outcome rather a starting point in this model is based on the notion that these 'outcomes' are related to the children's 'primary' conditions. They are thought to be important targets for prevention; and they address an aspect of child health services that has traditionally be less well addressed by health care sector.

The five constructs included in the proposed model are: background and context; child characteristics; caregiver strain; intrapsychic factors; and coping/supportive factors and health outcomes. Each construct categorizes separate factors influencing caregiver health, and is described in detail below, with reference to the existing literature. We acknowledge that there are many possible ways of thinking of the stress process and an infinite number of factors that could be considered. Building on the available literature we have selected those we felt were most relevant. This of course does not eliminate the possibility of adding additional factors, which can be included within the constructs of our model. The goal of developing and subsequently testing a complex model is to determine whether there are factors that are more salient in their impact on caregiver health and well-being, and whether this knowledge can assist in the planning of services to families with a child with CP in order to ameliorate some of the stress involved in this caregiving career. The model is illustrated in Figure 1.

\section{Development of the multidimensional model}

Arrows within the model were chosen with two criteria in mind: first, that there be clear evidence in the literature to support an association between variables; and second, that the relationship be defensible from a theoretical, causal standpoint. We have selected constructs and latent variables for which there is some evidence in the literature, however there might be other constructs such as availability and access to care that can easily be incorporated based on new emerging evidence. While some of the causal relationships among the factors depicted in the proposed model (Figure 1) are almost certainly bi-directional, including bi-directional effects in a model often results in practical difficulties of empirical testing of the models. For this reason, the unidirectional relationships were chosen on the basis of the direction that was more defensible in terms of a causal model, or for which there was empirical evidence (Table 1 and 2)

\section{Background/context}

Caregiving does not occur in isolation from one's social and experiential past or present, thus it must be considered within this context. The construct of background/ context is included to address the setting in which caregiving takes place, with emphasis on the social and economic characteristics of the family. In other works socioeconomic variables have emerged as key correlates of exposure to care related stressors, and socioeconomic resources may help to contain the extent to which a patient's condition becomes burdensome[8]. A socioeconomic status (SES) factor can be determined using measures of parental education, occupation, and family income. In light of previous research, we hypothesize that higher SES will be associated with fewer child behavior problems [24,48], fewer caregiving demands[16,24,48,53], and improved psychological and physical health $[9,31,39]$.

\section{Child characteristics}

The child characteristics construct constitutes factors that are objective conditions of caregiving, i.e. they are manifestations of the child's impairment and thus constitute actual care demands. The literature has pointed to disability of the child and child behavior problems as key factors associated with caregiver health. Disability of the child measures motor severity and cognitive functioning, the extent of dependence in activities of daily living (ADL), and any additional medical problems. We hypothesize that less severe disability will be associated with better psychological and physical health $[5,9,11,54,55]$, lower ratings of caregiver demands[56], and more positive parental perception of formal services as being family-centered[24,57]. Measures of child behavior problems assess behavioral issues such as conduct disorders, hyperactivity, emotional disorders, and somatization[11]. These behaviors require surveillance, control and exertion on the part of the caregiver. We hypothesize that fewer behavior problems will be associated with higher caregiver self-perception[37], and better psychological health[24,58]. 


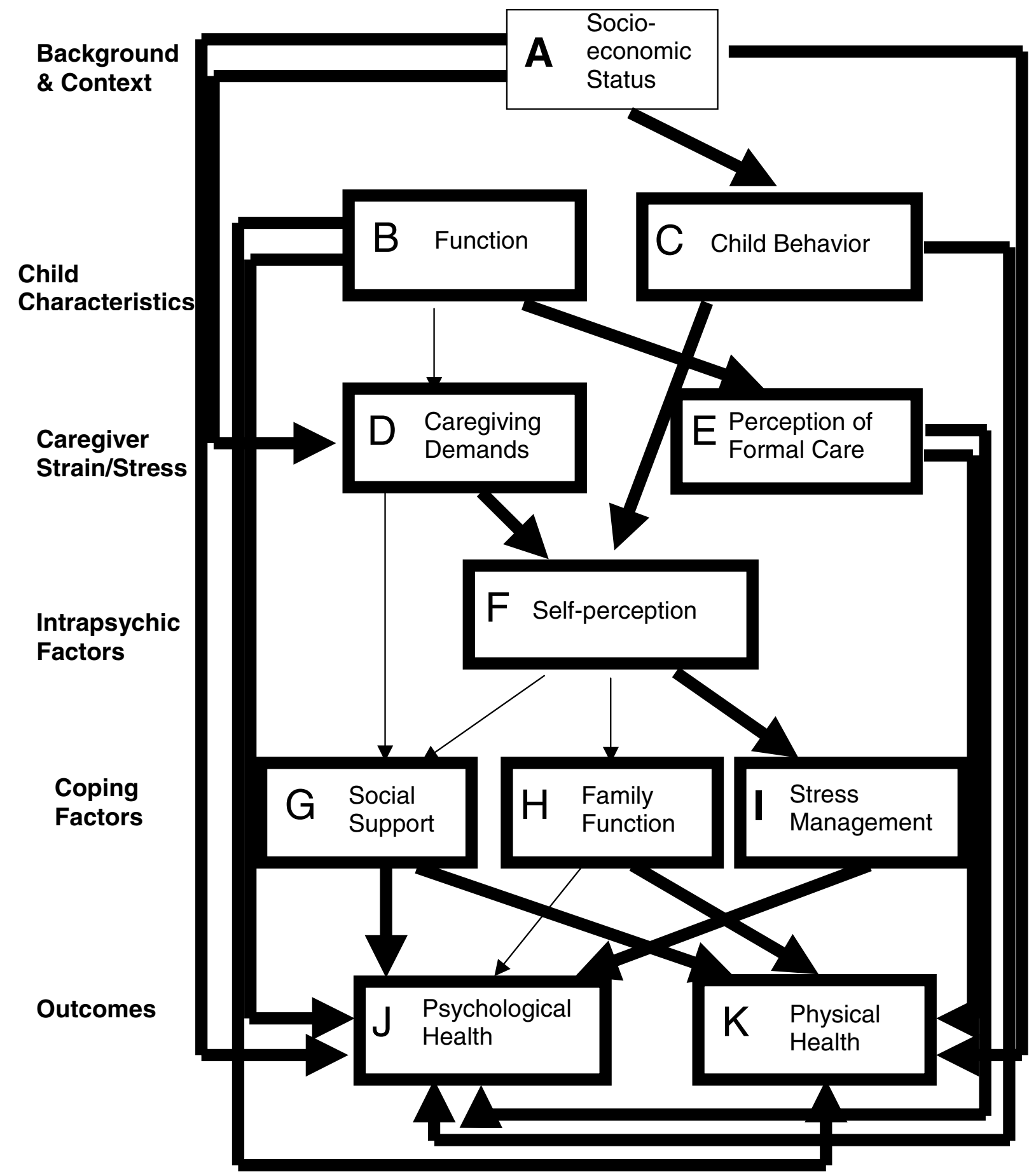

Figure I

Conceptual Model of Caregiving Process and Caregiver Burden Among Pediatric Population 


\section{Caregiver strain}

Factors considered under this construct are caregiving demands and perception of formal care. Caregiving demands measure the daily demands on the caregiver, as well as conflict between the caregiving role and occupational roles of the primary caregiver. We hypothesize that fewer demands will be associated with higher scores on measures of self-perception such as mastery and selfesteem[33], and increased levels of social support $[56,59,60]$. Perception of formal care measures the extent to which caregivers report formal services as being family-centered. We hypothesize that higher scores on this construct will be associated with better psychological and physical health[24].

\section{Caregiver intrapsychic factors}

The Intrapsychic factors construct pertains to the caregiver's internal state. For most individuals, caregiving constitutes a new social role; identification with the role often coincides with role incumbency and with the development of self-evaluation of how well one performs the role[8]. Self-perception is thus considered an important intrapsychic factor. Self-perception can be indicated with measures of the caregiver's self-esteem and sense of mastery over the caregiving situation. We hypothesize that higher levels of self-perception will be associated with higher perceived levels of social support[33,37,61], better family functioning [62-64] and higher use of stress management strategies[35,65,66].

\section{Coping/supportive factors}

People differ in their access to and use of coping factors. Previous research has shown that the factors included under this construct - social support, family function, and stress management - may serve as constraining resources with respect to caregiver health outcomes $[9,16,24,27,31,38,40,41,43,46,67]$. Social support measures informal support derived from the social relationships of the caregiver with extended family, friends and neighbors; family function measures the extent to which a family works as a unit; and stress management measures the number of strategies and practices of the caregiver in response to problematic situations. We hypothesize that higher scores on social support, family functioning, and stress management will be associated with better psychological health[9,16,24,27,38,40,46,67]. In addition, we hypothesize that higher scores on social support and family function will be associated with greater physical health of the caregiver[16,41,43].

\section{Caregiver health and well-being}

The two health outcomes considered in the proposed models are psychological health and physical health[68]. Psychological health measures distress and depression in the caregiver.

\section{Future directions: using structural equation modeling}

In a cross sectional study with caregivers of children with cerebral palsy, the proposed model (Figure 1) will use a single comprehensive Structural Equation Model (SEM) to examine simultaneously the five major constructs described in this paper and thought to be relevant to the health of caregivers. SEMs are primarily representations of causal relationships between hypothesized constructs, rather than just the simple associations between those constructs $[69,70]$. Each arrow in the model is therefore meant to indicate not simply an association between variables, but rather a theoretically-derived representation of the causal nature of that association. Our future research will therefore serve to test the proposed empirical model, and provide an example of a study that may be conducted under this new framework.

Our current research efforts are directed at testing this proposed model by conducting a cross-sectional study on caregivers of children with cerebral palsy. This paper outlines the variable measures and indicators that we have chosen for our study, which are congruent with our theoretical model.

Future studies using longitudinal data under this theoretical model could potentially provide many answers to the puzzles of caregiver health. The dynamic nature of the caregiving career might then be addressed empirically, which would help to provide insight into what stages are actually experienced by caregivers, and how these stages and the transitions between them can be made easier, potentially reducing the probability of negative health outcomes related to specific points along a dynamic continuum. Conducting a longitudinal study under the guidelines of the proposed model would therefore allow for increased specificity when determining the measures and assistance that should be implemented to relieve caregiver burden.

\section{Summary}

This conceptual paper documents the state of current knowledge, examines the current thinking that has been used to describe the caregiving process from two diverse but related fields - pediatrics and geriatrics, and proposes a comprehensive model that can guide future research in this area.

\section{Abbreviations}

ADL: Activities of Daily Living

CP: Cerebral Palsy

SEM: Structural Equation Modeling

SES: Socio-Economic status 


\section{Competing Interests}

None declared.

\section{Author's Contributions}

PR: review of the literature, conceptualization, writing and editing

MO: review of the literature, conceptualization and editing

HS: writing and editing

PeR: conceptualization and editing

GK: conceptualization and editing

JB: review of the literature and comments on the draft

DR: moderate contribution to the conceptualization and comments on the draft

MS: moderate contribution to the conceptualization and comments on the draft

SK: moderate contribution to the conceptualization and comments on the draft

MW: moderate contribution to the conceptualization and comments on the draft

SDW: moderate contribution to the conceptualization and comments on the draft

EW: moderate contribution to the conceptualization and comments on the draft

\section{Acknowledgements}

Dr. Raina holds a Canadian Institutes of Health Research (CIHR) Investigator Award, Dr. Rosenbaum holds a Canada Research Chair in Childhood Disability from CIHR and Dr. Walter is a CIHR Scientist.

\section{References}

I. Bax M: Terminology and classification of cerebral palsy. Developmental Medicine and Child Neurology 1964, 6:297.

2. Rosen MG, Dickinson JC: The incidence of cerebral palsy. American Journal ob Obstetrics and Oncology 1992, 167:423.

3. Dzienkowski RC, Smith KK, Dillow KA, Yucha CB: Cerebral palsy: a comprehensive review. Nurse Pract 1996, $21: 45-4,57$.

4. Blacher J: Sequential stages of parental adjustment to the birth of a child with handicaps: fact or artifact? Ment Retard 1984, 22:55-68.

5. Breslau N, Staruch KS, Mortimer E.A.,Jr.: Psychological distress in mothers of disabled children. Am J Dis Child 1982, 136:682-686.

6. Aneshensel CS, Pearlin LI, Mullan JT, Zarit SH, Whitlatch CJ: Profiles in caregiving; The unexpected career San Diego, Academic Press, Inc.; 1995.

7. Dumas $D$, Peron J, Peron $Y$ : Marriage and conjugal life in Canada. Volume 91-534E. Ottawa, Statistics Canada; 1992.

8. Eicher PS, Batshaw ML: Cerebral palsy. Pediatr Clin North Am 1993 , 40:537-55I.
9. Sloper P, Turner S: Risk and resistance factors in the adaptation of parents of children with severe physical disability. $J$ Child Psychol Psychiatry 1993, 34:167-188.

10. Wallander JL, Varni JW, Babani L, DeHaan CB, Wilcox KT, Banis HT: The social environment and the adaptation of mothers of physically handicapped children. J Pediatr Psychol 1989, | 4:37|-387.

II. Cadman D, Rosenbaum P, Boyle M, Offord DR: Children with chronic illness: family and parent demographic characteristics and psychosocial adjustment. Pediatrics 1991, 87:884-889.

12. McKinney $B$, Peterson RA: Predictors of stress in parents of developmentally disabled children. J Pediatr Psychol 1987, I 2: $133-150$

13. Dyson LL: Response to the presence of a child with disabilities: parental stress and family functioning over time. Am J Ment Retard 1993, 98:207-218.

14. Gowen JW, Johnson-Martin N, Goldman BD, Appelbaum M: Feelings of depression and parenting competence of mothers of handicapped and nonhandicapped infants: a longitudinal study. Am J Ment Retard 1989, 94:259-27I.

15. Kazak AE, Marvin RS: Differences, difficulties and adaptation: stress and social networks in families with a handicapped child. Family Relations 1984, 33:67-76.

16. Dunst C], Trivette CM, Cross AH: Mediating influences of social support: personal, family, and child outcomes. Am J Ment Defic 1986, 90:403-4I7.

17. Friedrich WN, Friedrich WL: Psychosocial assets of parents of handicapped and nonhandicapped children. Am J Ment Defic I98I, 85:55I-553.

18. Kitagawa EM, Hauser PM: Differential mortality in the United States: A study in socioeconomic epidemiology Cambridge, MA, Harvard University Press; 1973.

19. Haan MN, Kaplan GA, Syme SL: Socioeconomic status and health: old observations and new thoughts. Pathways to health: the role of social factors Edited by: BunkerJP, GombyDS and KehrerBH. Mento Park, CA, Henry Kaiser Family Foundation; 1989:76-135.

20. Freeman HE: Social factors iin the chronic disease. Handbook of medical sociology Edited by: LevineS, ReederLG and FreemanHE. Englewood Cliffs, NJ, Prentice-Hall; 1 972:63-107.

21. Rogot E, Sorlie PE, Johnson NJ, Glover CS, Treasure DWA: A mortality study of one million persons by demographic, social and economic factors. Volume No. 88-2896. Edited by: USDepartment of Helath and Human Services. Bethesda, MD, National Insittutes of Health; 198I.

22. Schulz R, O'Brien AT, Bookwala J, Fleissner K: Psychiatric and physical morbidity effects of dementia caregiving: prevalence, correlates, and causes. Gerontologist 1995, 35:77|-791.

23. Mittelman MS, Ferris SH, Shulman E, Steinberg G, Ambinder A, Mackell JA, Cohen J: A comprehensive support program: effect on depression in spouse-caregivers of AD patients. Gerontologist 1995, 35:792-802.

24. King G, King S, Rosenbaum P, goffin R: Family-centered caregiving and well-being of parents of children with disabilities: Linking process with outcome. Journal of pediatric psychology 1999 , 24:4I-53.

25. Beckman PJ: Influence of selected child characteristics on stress in families of handicapped infants. Am J Ment Defic 1983, 88: $150-156$

26. Friedrich WN, Wilturner LT, Cohen DS: Coping resources and parenting mentally retarded children. Am J Ment Defic 1985, 90:130-139.

27. Frey KS, Greenberg MT, Fewell RR: Stress and coping among parents of handicapped children: a multidimensional approach. Am J Ment Retard 1989, 94:240-249.

28. Sjobu L: Parents of children with cerebral palsy in Nordland (county in the north of Norway); factors connected to their quality of life and coping of the circumstances around the handicapped child. Arctic Med Res 1994, 53 Suppl I:30-3I.

29. Saddler AL, Hillman SB, Benjamins D: The influence of disabling condition visibility on family functioning. J Pediatr Psychol 1993 , I 8:425-439.

30. Leonard BJ, Johnson AL, Brust JD: Caregivers of children with disabilities: a comparison of those managing "OK" and those needing more help. Child Health Care 1993, 22:93-105. 
31. Lambrenos K, Weindling AM, Calam R, Cox AD: The effect of a child's disability on mother's mental health. Arch Dis Child I996, 74: II5- 120.

32. Trute B, Hiebert-Murphy D: Family adjustment to childhood developmental disability: a measure of parent appraisal of family impacts. J Pediatr Psychol 2002, 27:27I-280.

33. Skaff MM, Pearlin LI, Mullan JT: Transitions in the caregiving career: effects on sense of mastery. Psychol Aging 1996, I I:247-257.

34. Krause N: Stressors in salient social roles and well-being in later life. Journals of Gerontology 1994, 49: I37-I48.

35. Pearlin LI, Lieberman MA, Menaghan EG, Mullan JT: The stress process. J Health Soc Behav 198I, 22:337-356.

36. Ross CE, Mirowsky J: Explaining the social patterns of depression: control and problem solving--or support and talking? J Health Soc Behav 1989, 30:206-219.

37. Skaff MM, Pearlin Ll: Caregiving: role engulfment and the loss of self. Gerontologist 1992, 32:656-664.

38. Krause N: Perceived health problems, formal/informal support, and life satisfaction among older adults. J Gerontol 1990, 45:S193-S205.

39. Kiecolt-Glaser JK, Dura JR, Speicher CE, Trask OJ, Glaser R: Spousal caregivers of dementia victims: longitudinal changes in immunity and health. Psychosom Med 1991, 53:345-362.

40. Kronenberger WG, Thompson R.J.,Jr.: Psychological adaptation of mothers of children with spina bifida: association with dimensions of social relationships. J Pediatr Psychol 1992, I 7: I- I4.

4I. Fisher L, Ransom DC: An empirically derived typology of families: I. Relationships with adult health. Fam Process 1995, 34: $16|-| 82$.

42. Evans RL, Bishop DS, Ousley RT: Providing care to persons with physical disability. Effect on family caregivers. Am J Phys Med Rehabil 1992, 71:140-144.

43. Ransom DC, Fisher L, Terry HE: The California Family Health Project: II. Family world view and adult health. Fam Process 1992, 3 I:25|-267.

44. Friedrich WN: Predictors of the coping behavior of mothers of handicapped children. J Consult Clin Psychol 1979, 47: | |40-| |4 |

45. Erickson M, Upshur CC: Caretaking burden and social support: comparison of mothers of infants with and without disabilities. Am J Ment Retard 1989, 94:250-258.

46. Barakat LP, Linney JA: Children with physical handicaps and their mothers: the interrelation of social support, maternal adjustment, and child adjustment. J Pediatr Psychol 1992, 1 7:725-739.

47. Dutton DB, Levine S: Socioeconomic status and health: Overview, methodology critique, and reformation. Pathways to health: The role of social factors Edited by: BunkerJP, GombyDS and KehrerBH. Menlo Park, CA, Kaiser Family Foundation; 1 989:29-69.

48. Wallander JL, Varni JW, Babani L, Banis HT, DeHaan CB, Wilcox KT: Disability parameters, chronic strain, and adaptation of physically handicapped children and their mothers. J Pediatr Psychol 1989, 14:23-42.

49. Pearlin LI, Mullan JT, Semple SJ, Skaff MM: Caregiving and the stress process: an overview of concepts and their measures. Gerontologist 1990, 30:583-594.

50. Caserta MS, Lund DA, Wright SD: Exploring the Caregiver Burden Inventory (CBI): further evidence for a multidimensional view of burden. Int I Aging Hum Dev 1996, 43:21-34.

51. Morrissey E, Becker J, Rubert MP: Coping resources and depression in the caregiving spouses of Alzheimer patients. $\mathrm{Br} J \mathrm{Med}$ Psychol 1990, 63 (Pt 2): I6I-I7I.

52. Sisk RJ: Caregiver burden and health promotion. Int J Nurs Stud 2000, 37:37-43.

53. Blackman JA, Levine MD: A follow-up study of preschool children evaluated for developmental and behavioral problems. Clin Pediatr (Phila) 1987, 26:248-252.

54. Pless IB, Pinkerton P: Chronic Childhood disorders: Promoting patterns of development Chicago; 1975.

55. Silver EJ, Westbrook LE, Stein RE: Relationship of parental psychological distress to consequences of chronic health conditions in children. J Pediatr Psychol 1998, 23:5-I5.

56. Palfrey JS, Walker DK, Butler JA, Singer JD: Patterns of response in families of chronically disabled children: an assessment in five metropolitan school districts. Am J Orthopsychiatry 1989, 59:94-104.
57. King GA, King SM, Rosenbaum PL: How mothers and fathers view professional caregiving for children with disabilities. Dev Med Child Neurol 1996, 38:397-407.

58. Quittner AL, Glueckauf RL, Jackson DN: Chronic parenting stress: moderating versus mediating effects of social support. J Pers Soc Psychol 1990, 59: I266-1278.

59. Musil CM: Health, stress, coping, and social support in grandmother caregivers. Health Care Women Int 1998, 19:44 I-455.

60. MaloneBeach EE, Zarit SH: Dimensions of social support and social conflict as predictors of caregiver depression. Int Psychogeriatr 1995, 7:25-38.

61. Caplan G: Mastery of stress: psychosocial aspects. Am J Psychiatry I981, I 38:413-420.

62. Brown GW, Andrews B, Harris T, Adler Z, Bridge L: Social support, self-esteem and depression. Psychol Med 1986, I 6:813-83।.

63. Robinson K: The relationships between social skills, social support, self-esteem and burden in adult caregivers. J Adv Nurs 1990, I 5:788-795.

64. Schill T, Beyler J, Morales J, Ekstrom B: Self-defeating personality and perceptions of family environment. Psychol Rep I99I, 69:744-746.

65. Hobfoll SE, Walfisch S: Coping with a threat to life: a longitudinal study of self-concept, social support, and psychological distress. Am J Community Psychol 1984, I 2:87-100.

66. Mowat J, Laschinger HK: Self-efficacy in caregivers of cognitively impaired elderly people: a concept analysis. J Adv Nurs 1994, 19:1105-III3.

67. Scharlach AE, Boyd SL: Caregiving and employment: results of an employee survey. Gerontologist 1989, 29:382-387.

68. Ware J.E.,Jr., Sherbourne CD: The MOS 36-item short-form health survey (SF-36). I. Conceptual framework and item selection. Med Care 1992, 30:473-483.

69. Hayduk LA: Structural Equation Modeling with LISREL Baltimore, The Johns Hopkins University Press; 1987.

70. Anderson JC, Gerbing DW: Structural equation modeling in practice. Psychological Bulletin 1988, 103:41 I-I23.

\section{Pre-publication history}

The pre-publication history for this paper can be accessed here:

http://www.biomedcentral.com/1471-2431/4/1/prepub
Publish with Bio Med Central and every scientist can read your work free of charge

"BioMed Central will be the most significant development for disseminating the results of biomedical research in our lifetime. "

Sir Paul Nurse, Cancer Research UK

Your research papers will be:

- available free of charge to the entire biomedical community

- peer reviewed and published immediately upon acceptance

- cited in PubMed and archived on PubMed Central

- yours - you keep the copyright

Submit your manuscript here:

http://www.biomedcentral.com/info/publishing_adv.asp
BioMedcentral 